\title{
Regeneração in vitro de Parapiptadenia rigida
}

\author{
In vitro regeneration of Parapiptadenia rigida
}

\author{
Paula Kielse $^{\mathrm{I}^{*}}$ Elci Terezinha Henz Franco $^{\mathrm{I}}$ Juçara Terezinha Paranhos $^{\mathrm{II}}$ \\ Ana Paula Santos de LimaII
}

\section{RESUMO}

O objetivo deste trabalho é estabelecer um protocolo de micropropagação para a Parapiptadenia rigida utilizando explantes de plântulas assépticas obtidas da germinação de sementes in vitro. Para a indução de brotos, segmentos cotiledonares e nodais foram inoculados em meio de cultura 1/2 WPM acrescido de 0; 0,25;0,50; 1,0mg $\mathrm{L}^{-1}$ de BAP ou KIN. O enraizamento dos explantes com broto foi realizado em meio $1 / 4$ WPM suplementado com $0 ; 0,25 ; 1,0$; $1,75 \mathrm{mg} \mathrm{L}^{-1}$ de AIB. Não foi necessária a adição de citocinina ao meio para indução de brotos em segmento cotiledonar e nodal. Contudo, a dose de $0,50 \mathrm{mg} \mathrm{L}^{-1}$, independente do tipo de citocinina, promoveu maior tamanho dos brotos e maior número de folhas por broto. O maior potencial de enraizamento ocorreu em segmentos cotiledonares inoculados em meio contendo $1,0 \mathrm{mg} L^{-1}$ de AIB. A utilização desse protocolo de regeneração permite a obtenção de mudas de Parapiptadenia rigida.

Palavras-chave: angico-vermelho, enraizamento, micropropagação, fitorregulador.

\section{ABSTRACT}

The aim of this research is to develop a micropropagation protocol for Parapiptadenia rigida using aseptic seedling explants from in vitro germinated seeds. To the sprout induction, cotyledonary and nodal segments were inoculated in a $1 / 2$ WPM culture medium containing $0 ; 0.25$; $0.50 ; 1.0 \mathrm{mg} \mathrm{L}^{-1}$ of BAP or KIN. The rooting of sprouted explants was rooted in a $1 / 4$ WPM culture medium containing $0 ; 0.25$; $1.0 ; 1.75 \mathrm{mg} \mathrm{L}^{-1}$ of IBA. It was not necessary the addition of cytokinin in medium to induce sprouting in cotyledonary and nodal segments. However, the doses of $0.50 \mathrm{mg} \mathrm{L}^{-1}$, independently of cytokinin type, promoted greater size of sprouts and the largest number of leaves per sprout. The highest rooting potential occurred in cotyledonary segments inoculated in medium with $1.0 \mathrm{mg} \mathrm{L}^{-1}$ of IBA. The use of this regeneration protocol allows obtaining Parapiptadenia rigida seedlings.

Key words: red angico, rooting, micropropagation, plant growth regulator.

\section{INTRODUÇÃO}

Parapiptadenia rigida Bretham Brenan (Fabaceae), popularmente conhecida por angicovermelho (SOBRAL et al., 2006), é uma espécie florestal com relevante importância na reposição de mata ciliar e no reflorestamento misto de áreas degradadas. Sua madeira apresenta múltiplos usos, a casca possui reconhecida propriedade medicinal, além de ser rica em tanino, com ampla utilização na indústria de curtume (LORENZI, 2000).

O estabelecimento in vitro de explantes corresponde à primeira etapa de um sistema de micropropagação, com início na seleção dos explantes mais adequados para posterior multiplicação. O tipo de explante deve ser escolhido de acordo com a sua capacidade para se adequar às condições in vitro, sendo recomendados os que contenham maior proporção de tecido meristemático por apresentarem uma maior capacidade de expressar a totipotência. A utilização de segmento nodal é um método direto de

IDepartamento de Ciências Florestais, Universidade Federal de Santa Maria (UFSM), 97105-900, Santa Maria, RS, Brasil. E-mail: paulakielse@yahoo.com.br. *Autor para correspondência.

IIDepartamento de Biologia, Centro de Ciências Naturais e Exatas (CCNE), UFSM, Santa Maria, RS, Brasil. 
regeneração de plantas, baseado na indução do crescimento e proliferação de gemas vegetativas axilares pré-formadas. Os segmentos nodais contendo as gemas são isolados e inoculados in vitro, sendo estas estimuladas ao crescimento, dando origem a brotos (GRATTAPAGLIA \& MACHADO, 1998).

Para a indução dos processos de desdiferenciação e rediferenciação responsáveis pela formação de tecidos e órgãos, além da escolha do explante mais adequado, se faz necessário o uso de fitorreguladores capazes de estimular a formação de parte aérea e raízes. A indução de brotos em explantes pode ser realizada por meio da aplicação de citocininas exógenas, promovendo o crescimento inicial das gemas axilares pela quebra da dominância apical (TAIZ \& ZEIGER, 2004). As citocininas 6-benzilaminopurina (BAP) e cinetina (KIN) são comumente utilizadas na cultura de tecidos e, segundo HU \& WANG (1983), apresentam diferença quanto ao potencial de indução dos brotos nos explante. As auxinas atuam na expansão, no alongamento e na divisão celular, atuando antes do primeiro evento de formação do primórdio radicular, ou seja, pouco antes da desdiferenciação e formação do lócus meristemático, sugerindo que a função da auxina no enraizamento esteja associada somente à indução radicular (BLAKESLEY et al., 1991b). O ácido indolbutírico (AIB) tem sido a auxina mais empregada para a indução de raízes adventícias em explantes, especialmente em razão da sua maior fotoestabilidade (HOFFMANN et al., 1996).

Apesar de a Parapiptadenia rigida produzir anualmente grande quantidade de sementes viáveis, estas têm comportamento recalcitrante com relação ao armazenamento e perdem sua viabilidade em um curto período de tempo, dificultando sua propagação via sexuada (CARVALHO, 2003). Além disso, na maioria das espécies lenhosas, o enraizamento é a etapa mais difícil e, apesar dos avanços da técnica de cultura de tecidos, o estabelecimento de protocolos eficientes que estimulem a rizogênese dessas plantas ainda é limitado, especialmente por serem recalcitrantes ao enraizamento. Nesse contexto, o objetivo deste trabalho é estabelecer um protocolo de propagação in vitro da Parapiptadenia rigida utilizando explantes de plântulas assépticas obtidas da germinação de sementes in vitro.

\section{MATERIAL E MÉTODOS}

O estudo foi conduzido no Laboratório de Cultura de Tecidos Vegetais, do Departamento de Biologia, Centro de Ciências Naturais e Exatas, da Universidade Federal de Santa Maria. As culturas foram mantidas em sala de crescimento a $25 \pm 1^{\circ} \mathrm{C}$, com fotoperíodo de 16 horas, sob densidade de fluxo de fótons de aproximadamente 1500 lux, fornecida por lâmpadas fluorescentes branco-frias. O meio de cultura utilizado foi o WPM (LLOYD \& McCOWN, 1980), com $1 / 2$ ou $1 / 4$ da quantidade de sais e $\mathrm{pH}$ ajustado para $5,8 \pm 0,2$. Os meios foram distribuídos em frascos (30mm de diâmetro e 70mm de altura) ou tubos de ensaio (20,50mm de diâmetro e $150 \mathrm{~mm}$ de altura) e, posteriormente, fechados com papel alumínio para esterilização em autoclave por 20 minutos à temperatura de $121^{\circ} \mathrm{C}$ e pressão de $1 \mathrm{~atm}$.

Para obtenção das plântulas assépticas, sementes de Parapiptadenia rigida foram submetidas a um pré-tratamento de desinfestação em álcool 70\% por um minuto. Em seguida, as sementes foram imersas em água sanitária na concentração de 2,5\% de cloro ativo acrescida de três gotas de detergente Tween 20, durante 30 minutos, com posterior enxágüe em água destilada e autoclavada (KIELSE et al., 2007). Posteriormente, as sementes foram imersas em solução do fungicida Benomil ${ }^{\circledR}$ na dose de $1 \mathrm{~g} \mathrm{~L}^{-1}$, durante 10 minutos, e inoculadas em tubos de ensaio contendo $15 \mathrm{~mL}$ de meio WPM acrescido de $20 \mathrm{~g} \mathrm{~L}^{-1}$ de sacarose e $5 \mathrm{mg} \mathrm{L}^{-1}$ de ágar.

A indução de brotos foi realizada nos segmentos cotiledonar e nodal obtidos de plântulas assépticas com 50 dias de idade, com tamanho aproximado de $1 \mathrm{~cm}$, e uma gema axilar nos segmentos nodais. Os explantes foram inoculados verticalmente em frascos contendo 1/2 WPM acrescido de $30 \mathrm{~g} \mathrm{~L}^{-1}$ de sacarose e $6 \mathrm{~g} \mathrm{~L}^{-1}$ de ágar, na quantidade de $30 \mathrm{~mL}$ de meio por frasco. Para a indução de brotos, utilizou-se como tratamentos as doses de $0 ; 0,25 ; 0,50 ; 1,0 \mathrm{mg} \mathrm{L}^{-1}$ de BAP ou KIN. O delineamento utilizado foi o inteiramente casualizado, em esquema fatorial $2 \times 2 \times 4$ (tipo de segmento $\mathrm{x}$ tipo de citocinina $\mathrm{x}$ dose hormonal), com cinco repetições de seis explantes por tratamento. Aos 30 dias após a inoculação, os explantes foram subcultivados para meio de cultura livre de fitorregulador, permanecendo por mais 30 dias nessas condições. Aos 60 dias da inoculação, avaliaram-se a porcentagem de brotos formados, o tamanho dos brotos e o número de folhas por broto.

O enraizamento foi realizado nos segmentos cotiledonar e nodal tratados com $0,50 \mathrm{mg} \mathrm{L}^{-1}$ de BAP ou KIN durante a fase de indução de brotos, sem a retirada dos brotos formados durante essa fase. Os explantes foram inoculados em tubos de ensaio contendo meio 1/4 WPM acrescido de $30 \mathrm{~g} \mathrm{~L}^{-1}$ de sacarose, $6 \mathrm{~g} \mathrm{~L}^{-1}$ de ágar, $1,5 \mathrm{~g} \mathrm{~L}^{-1}$ de carvão ativado, na quantidade de $20 \mathrm{~mL}$ de meio por tubo. Para indução de raízes, foram testadas as doses de $0 ; 0,25 ; 1,0 ; 1,75 \mathrm{mg} \mathrm{L}^{-1}$ de AIB. O 
delineamento foi o inteiramente casualizado, em arranjo fatorial 2x4 (tipo de segmento $\mathrm{x}$ dose hormonal), com quatro repetições de três explantes por tratamento. Aos 60 dias da inoculação, avaliaram-se a porcentagem de enraizamento, o número de raízes por explante, o comprimento da raiz mais longa $(\mathrm{cm})$, a porcentagem de explantes com calo na base e o tamanho dos calos (cm).

Para a aclimatização das plantas regeneradas, realizou-se a abertura gradativa dos tubos em sala de crescimento, por meio de perfurações no filme PVC, durante sete dias. Após esse período, as plantas foram transplantadas para copos plásticos contendo substrato composto por vermiculita e Plantmax ${ }^{\circledR}(2: 1 \mathrm{v} /$ v) esterilizado em autoclave por 40 minutos; sendo cobertas individualmente por garrafas plásticas. As plantas permaneceram em ambiente com luminosidade, temperatura e umidade do ar sob condições naturais por sete dias. Durante esse período, a irrigação foi realizada a cada dois dias, por meio de aspersão manual. Posteriormente, as garrafas plásticas foram substituídas por campânulas plásticas (miniestufas), sendo as irrigações realizadas três vezes por semana por aspersão manual, além da rega do substrato duas vezes por semana. Aos 60 dias após o transplante, avaliouse a porcentagem de sobrevivência das plantas.

Os dados qualitativos foram avaliados por análise de variância, com médias comparadas pelo teste de Tukey a 5\% de significância; e os dados quantitativos submetidos à análise de regressão.

\section{RESULTADOS E DISCUSSÃO}

Para a porcentagem de explantes de Parapiptadenia rigida com broto, houve interação entre o tipo de segmento e o tipo de fitorregulador, indicando que os fatores não são independentes. A maior porcentagem de explantes com broto ocorreu em segmento cotiledonar inoculado em meio contendo BAP (98,75\%), não diferindo significativamente dos tratamentos utilizando o mesmo tipo de segmento em meio acrescido de KIN, independente da dose de fitorregulador (Figura 1A).

Ainda com relação à porcentagem de explantes com broto, houve interação entre o tipo de segmento e a dose de fitorregulador. As maiores porcentagens de explantes com broto (100\%) ocorreram em segmento cotiledonar tratado com 0,25 e $0,50 \mathrm{mg} \mathrm{L}^{-1}$, independente do tipo de fitorregulador, e no meio controle (Figura 2A). A formação de brotos mesmo nos explantes inoculados em meio livre de fitorregulador indica que não há necessidade de uma fonte exógena de citocinina para estimular a brotação em segmentos cotiledonar e nodal de Parapiptadenia rigida. Contudo, a adição de BAP ou KIN ao meio favoreceu a formação de brotos em segmento nodal (Figura 2A).

Para o parâmetro tamanho dos brotos, não foi verificada interação entre o tipo de segmento, o tipo e a dose de fitorregulador. O maior tamanho médio de brotos $(0,43 \mathrm{~cm})$ ocorreu em segmento cotiledonar, diferindo significativamente do segmento nodal (0,22cm, Figura 1B). GRIGOLETTO (1997), em estudo de regeneração in vitro de mangabeira (Hanconia speciosa), também observou a formação de brotos com maior tamanho em segmento cotiledonar, independente da dose de fitorregulador utilizada.

Em função das doses de fitorregulador, o maior tamanho médio de brotos $(0,47 \mathrm{~cm})$ ocorreu em explantes de Parapiptadenia rigida tratados com 0,50 $\mathrm{mg} \mathrm{L}^{-1}$ de citocinina, independente do tipo de fitorregulador (Figura 2B). Resultado similar foi encontrado por NOBRE \& ROMANO (1998), em estudo de multiplicação in vitro de fícus (Ficus carica), observando brotos com maior tamanho em segmento nodal inoculado em meio contendo $0,50 \mathrm{mg} \mathrm{L}^{-1}$ de KIN.

As citocininas podem favorecer $\mathrm{O}$ alongamento de brotos; contudo, é necessário que se adicione ao meio a dose adequada, sendo esta específica para cada espécie (GRATTAPAGLIA \& MACHADO, 1998). Em Parapiptadenia rigida ocorreu um efeito negativo no tamanho dos brotos formados em explantes tratados com 1,0mg L ${ }^{-1}$, independente do tipo de fitorregulador (Figura 2B). SOUZA et al. (2003), estudando a multiplicação in vitro de arnica (Lychnophora pinaster), verificaram brotos mais alongados em segmento nodal inoculado em meio contendo 0,07mg L-1 de BAP. Já MANTOVANI et al. (1999) observaram que o segmento nodal de caixeta (Didymopanax morototoni) inoculado em meio acrescido de $1,0 \mathrm{mg} \mathrm{L}^{-1}$ de BAP apresentou um maior alongamento de brotos. Para a acácia-negra (Acacia mearnsii), houve um efeito negativo no crescimento dos brotos quando utilizada a dose de $2,0 \mathrm{mg} \mathrm{L}^{-1}$ de BAP (BORGES JÚNIOR et al., 2004).

Para o parâmetro o número de folhas por broto de Parapiptadenia rigida, houve interação entre o tipo de segmento e a dose de fitorregulador. O maior número médio de folhas $(2,90)$ ocorreu em segmento cotiledonar inoculado em meio contendo $0,50 \mathrm{mg} \mathrm{L}^{-1} \mathrm{de}$ KIN, independente do tipo de fitorregulador (Figura 2C). Os brotos apresentaram, em geral, folhas verdes e vigorosas. Em segmento cotiledonar tratado com BAP, houve a formação de brotação múltipla, sobretudo na dose de 1,0mg $\mathrm{L}^{-1}$ da citocinina, evento não observado nos tratamentos contendo KIN (dados não demonstrados). A presença de brotação múltipla 

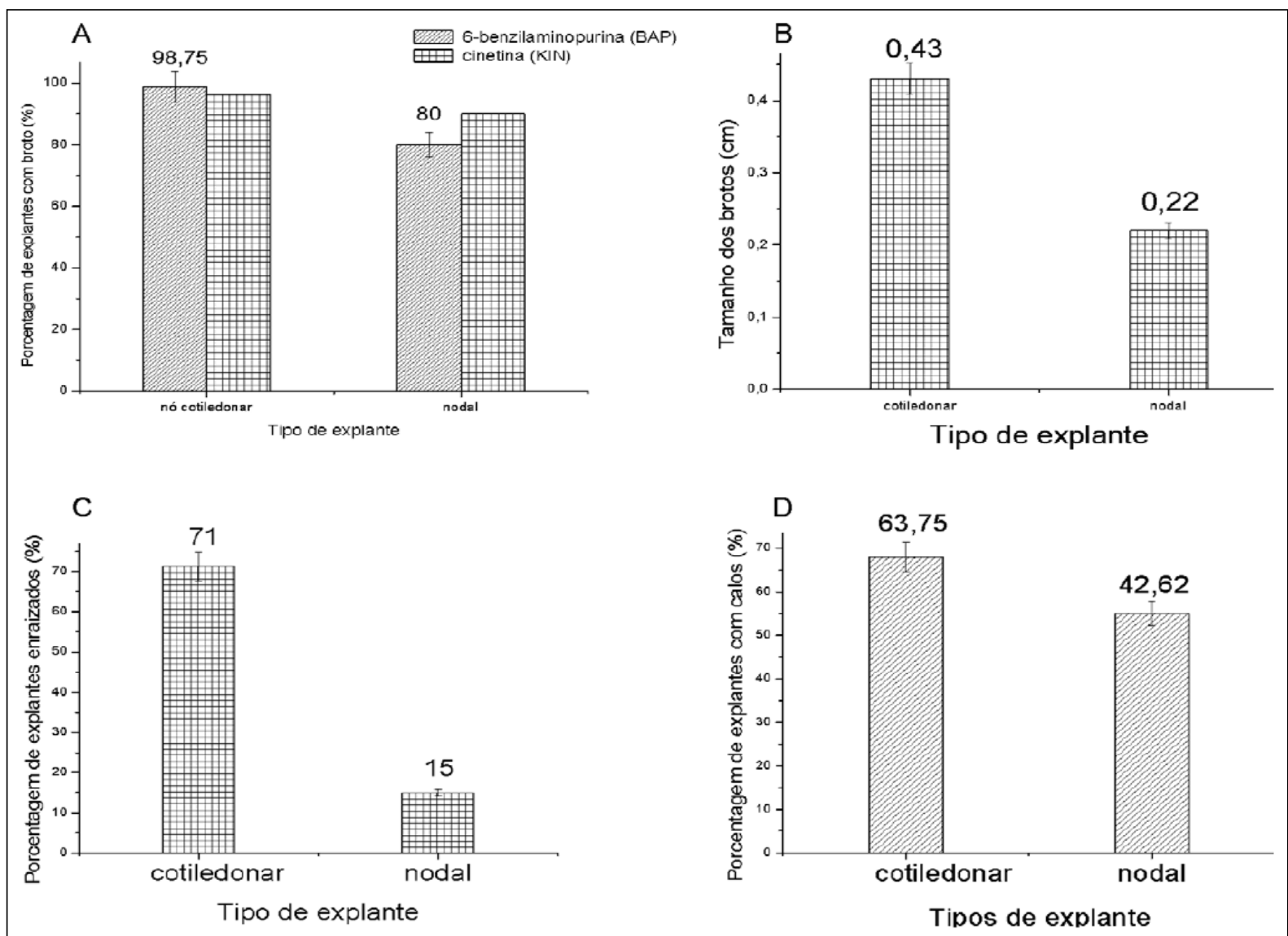

Figura 1 - Respostas morfogênicas em segmentos cotiledonar e nodal de Parapiptadenia rigida inoculados na fase de indução de brotos em meio $1 / 2$ WPM (LLOYD \& McCOWN, 1980) acrescido de 0; 0,25; 0,50; 1,0 $\mathrm{mg} \mathrm{L}^{-1}$ de 6-benzilaminopurina (BAP) ou cinetina (KIN) e enraizados em meio 1/4 WPM acrescido de $0 ; 0,50 ; 1,0 ; 1,75 \mathrm{mg} \mathrm{L}^{-1}$ de ácido indolbutírico (AIB), avaliados 60 dias após a inoculação em cada fase de cultivo: (A) porcentagem de explantes com broto, independente das doses de citocinina; (B) tamanho dos brotos, independente do tipo e da dose de citocinina; (C) porcentagem de explantes enraizados, independente das doses de AIB; (D) porcentagem de explantes com formação de calo na base durante a fase de indução rizogênica.

somente nos meios suplementados com BAP, provavelmente, ocorreu em conseqüência dessa citocinina ser mais ativa que a KIN (HU \& WANG, 1983). Dessa forma, o aumento da dose de BAP no meio pode ter ocasionado um maior número de divisões celulares e, conseqüentemente, maior indução de brotos em segmento cotiledonar. Em segmento nodal, as doses de BAP utilizadas não provocaram tal efeito, possivelmente em razão desse tipo de segmento apresentar menor nível endógeno de citocinina.

Para a porcentagem de enraizamento de explantes de Parapiptadenia rigida, não houve interação entre os fatores tipo de segmento e dose de AIB. O segmento cotiledonar apresentou a maior porcentagem de explantes enraizados (71\%), diferindo significativamente do segmento nodal (15\%), independente da dose de AIB utilizada (Figura 1C). O maior potencial de enraizamento observado em segmento cotiledonar pode estar relacionado com seu melhor desempenho na fase de indução de brotos. Durante a formação de raízes adventícias existe uma interação entre a auxina fornecida e os cofatores que atuam sinergicamente nessas raízes. Esses fatores são sintetizados em gemas e folhas jovens, sendo transportados pelo floema a partir do local de síntese (FACHINELLO et al., 1995). FORD et al. (2001) sugerem que o AIB aplicado exogenamente é rapidamente transportado até as folhas, ativando uma maior produção de ácido indolacético (AIA), com posterior transporte até a região de iniciação radicular.

Para o parâmetro número de raízes por explante, houve interação entre o tipo de segmento e a dose de AIB. O maior número de raízes $(1,95)$ ocorreu em segmento cotiledonar tratado com $1,0 \mathrm{mg} \mathrm{L}^{-1}$ de AIB (Figura 2D). Essa mesma dose promoveu o maior número de raízes em segmento nodal, entretanto com 


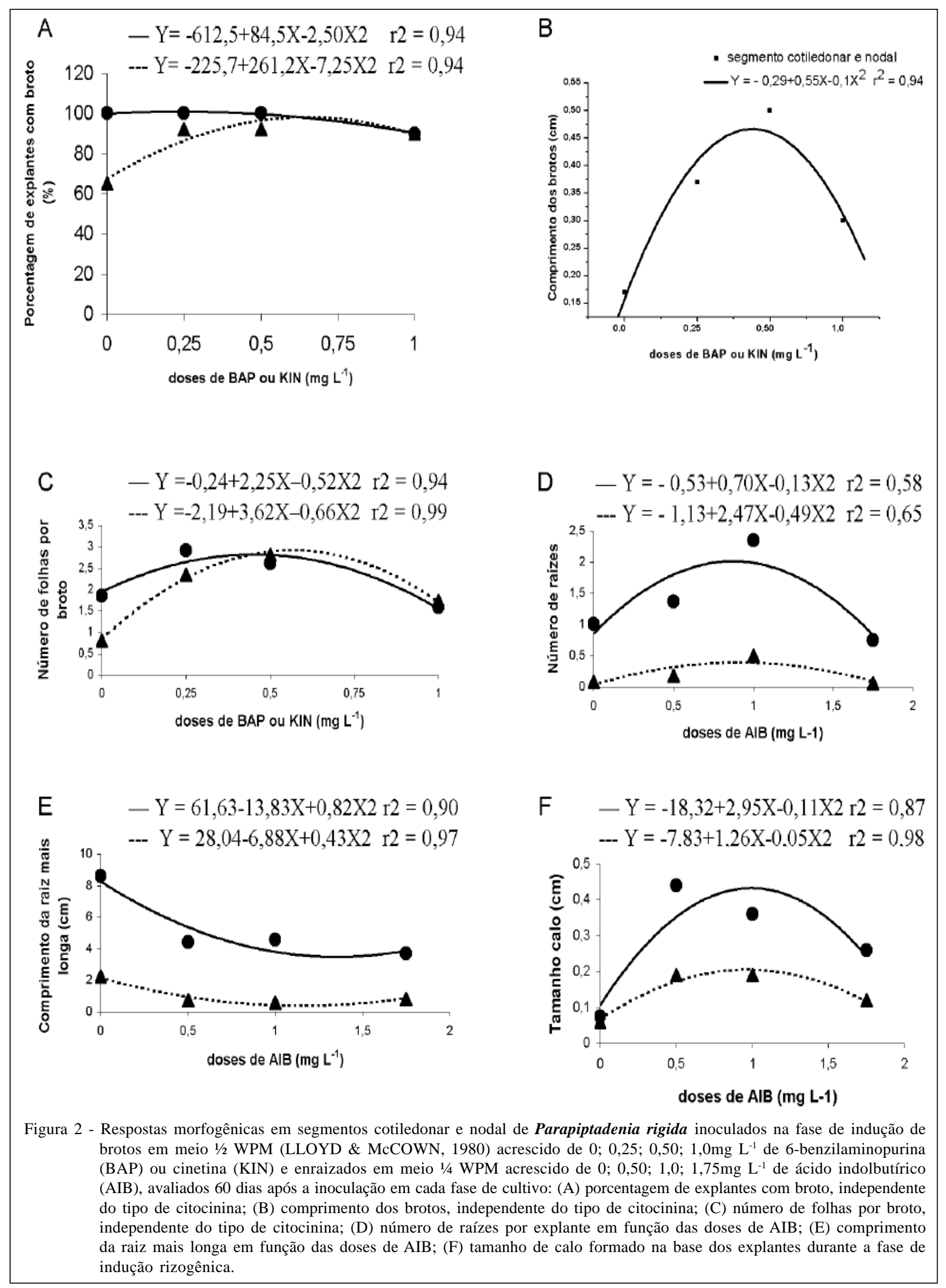

Ciência Rural, v.39, n.4, jul, 2009. 
valor consideravelmente inferior ao valor observado em segmento cotiledonar. Foi verificado um efeito negativo no número de raízes, tanto em segmento cotiledonar quanto em segmento nodal, quando utilizada a dose de $1,75 \mathrm{mg} \mathrm{L}^{-1}$ de AIB (Figura 2D). GALSTON \& DAVIES (1972) mencionam que, quando a auxina é aplicada em partes cortadas de plantas, a maior dose aumenta o efeito até um máximo, acima do qual qualquer acréscimo se torna fitotóxico. Em Parapiptadenia rigida, possivelmente a dose de $1,75 \mathrm{mg} \mathrm{L}^{-1}$ de AIB tenha provocado toxidez, inibindo a formação de raízes nos explantes.

Para o comprimento da raiz mais longa, foi observado um efeito negativo à medida que se aumentou a dose de AIB. O maior comprimento médio $(8,62 \mathrm{~cm})$ ocorreu em segmento cotiledonar inoculado em meio livre de fitorregulador, seguido do mesmo tipo de segmento tratado com $1,0 \mathrm{mg} \mathrm{L}^{-1}$ de AIB $(4,60 \mathrm{~cm})$ (Figura 2E). HARTMANN et al. (2002) mencionam que o AIB estimula as plantas a produzirem raízes maiores. Esse evento não foi observado em segmento cotiledonar e nodal de Parapiptadenia rigida, visto apresentarem maior crescimento de raízes nos tratamentos controle (Figura 2E). Por outro lado, os mesmos autores citam que a auxina proporciona a formação de raízes mais fortes e fibrosas, sendo o mesmo verificado nos explantes tratados com $1,0 \mathrm{mg} \mathrm{L}^{-1}$ de AIB.

As raízes formadas nos explantes de Parapiptadenia rigida apresentaram coloração amarelada, sendo observados, em segmento cotiledonar, raízes secundárias e pêlos absorventes (dados não demonstrados). Houve formação calogênica na base dos explantes, com maior porcentagem de calos $(63,75 \%)$ em segmento cotiledonar, sem diferir significativamente do segmento nodal (42,62\%) (Figura 1D). O segmento cotiledonar inoculado em meio contendo 0,25 $\mathrm{mg} \mathrm{L}^{-1}$ de AIB apresentou o maior tamanho de calo $(0,44 \mathrm{~cm}$, Figura $2 \mathrm{~F})$. Possivelmente, nesse tipo de explante exista maior nível endógeno de auxina que, em balanço com os níveis de BAP ou KIN adicionados ao meio durante a fase de indução de brotos, promoveu uma maior proliferação de calos, como sugere a teoria do balanço hormonal formulada por SKOOG \& MILLER (1975). LEONEL et al. (1994) mencionam que a formação de calo pode ser o primeiro passo para a formação do sistema radicular; contudo, a presença deste tem sido relatada como uma desvantagem para a sobrevivência de plantas no campo.

Quanto à aclimatização das plantas regeneradas, a maior porcentagem de sobrevivência ocorreu em mudas provenientes do enraizamento de segmento cotiledonar em meio contendo $1,0 \mathrm{mg} \mathrm{L}^{-1} \mathrm{de}$ AIB (Tabela 1). Por outro lado, as plantas obtidas do
Tabela 1 - Porcentagem de sobrevivência de mudas de Parapiptadenia rigida advindas do enraizamento de segmentos cotiledonar e nodal em meio contendo 1/4 WPM acrescido de $0 ; 0,25 ; 1,0$; 1,75mg $\mathrm{L}^{-1}$ de AIB, avaliadas 60 dias após a aclimatização.

Sobrevivência das mudas após aclimatização

(\%)

\begin{tabular}{|c|c|c|}
\hline \multirow[b]{2}{*}{ AIB (mg L $\left.{ }^{-1}\right)$} & \multicolumn{2}{|c|}{---------------Explante de origem-------------- } \\
\hline & Segmento cotiledonar & Segmento nodal \\
\hline 0,00 & $33 b^{*}$ & $0 \mathrm{a}$ \\
\hline 0,25 & $20 \mathrm{~b}$ & $0 \mathrm{a}$ \\
\hline 1,00 & 68 a & $7 \mathrm{a}$ \\
\hline 1,75 & $35 \mathrm{~b}$ & 5 a \\
\hline Média & 21,00 & \\
\hline $\mathrm{CV} \%$ & 45,75 & \\
\hline
\end{tabular}

* Médias não seguidas por mesma letra na vertical diferem pelo teste de Tukey a $5 \%$ de probabilidade de erro.

enraizamento de segmento nodal mostraram-se sensíveis à transferência para o ambiente ex vitro, independente dos meios de origem. A menor porcentagem de sobrevivência das mudas obtidas partindo de segmento nodal pode estar relacionada às baixas respostas morfogênicas observadas nesse tipo de explante, especialmente durante a fase de enraizamento.

\section{CONCLUSÃO}

Não é necessária a adição de citocinina para a indução de brotos em segmentos cotiledonar e nodal de Parapiptadenia rigida; contudo, a dose de 0,50mg $\mathrm{L}^{-1}$ de BAP ou KIN promoveu o maior alongamento dos brotos e o maior número de folhas. Segmentos cotiledonares tratados com $1,0 \mathrm{mg}$. $\mathrm{L}^{-1}$ de AIB apresentam maior potencial de enraizamento e forneceram mudas com maior capacidade de sobrevivência durante a aclimatização.

\section{AGRADECIMENTO}

Os autores agradecem à Coordenação de Aperfeiçoamento de Pessoal de Nível Superior (Capes), pela concessão de bolsa a Paula Kielse.

\section{REFERÊNCIAS}

BLAKESLEY, D. et al. The role endogenous auxin in root initiation. Plant Growth Regulation, Nedherlands, v.10, p.341-353, 1991b. Disponível em: <http:// www.springerlink.com.w10050.dotlib.com.br/content/ t $8175 \mathrm{n} 1$ t $315 \mathrm{~h} 1803 /$ ? p = 79 a 72 c 7 f 7 c $0840 \mathrm{ff} 89$ b 984509dcbc38e\&pi=19>. Doi: 0.1007/BF00024593. 
BORGES JÚNIOR, N. et al. Multiplicação in vitro de gemas axilares de acácia-negra (Acacia mearnsii De Wild.). Revista Árvore, Viçosa, v.28, n.4, p.493-498, 2004. Disponível em: <http://www.scielo.br/ scielo.php?script=sci_arttext\&pid=S0100-67622004000400004>. Doi: 10.1590/S0100-67622004000400004.

CARVALHO, P.E.R. Espécies arbóreas brasileiras. Colombo - PR: Empresa Brasileira de Pesquisa Agropecuária, Centro Nacional de Pesquisa de Florestas - EMBRAPA - CNPF, 2003. 1039p.

FACHINELlO, J.C. et al. Propagação de plantas frutíferas de clima temperado. 2.ed. Pelotas: UFPel, 1995. 179p.

FORD, Y.Y. et al. Adventitious rooting: examining the role of auxin in easy and a difficult-to-root plant. Plant Growth Regulation, Nedherlands, v.36, n.2, p.149-159, 2002. Disponível em: <http://www.springerlink.com.w10050.dotlib.com.br/content/ d d g $65 \mathrm{w} \mathrm{k} \mathrm{rvlx} \mathrm{a} 59$ q k / ? p = d e 2 f 551 d a 68545 c0a1a69b2b66760b46\&pi=13>. Doi: 10.1023/A:1015013025513.

GALSTON, A.W.; DAVIES, P.J. Mecanismo de controle no desenvolvimento vegetal. 2.ed. São Paulo: Universidade de São Paulo, 1972. 171p.

GRATTAPAGLIA, D.; MACHADO, M.A. Micropropagação. In: TORRES, A.C. et al. (Eds). Cultura de tecidos e transformação genética de plantas. Brasília: CBABEMBRAPA, 1998. p.183-260.

GRIGOLETTO, E.R. Micropropagação de Hancornia speciosa Gomez (Mangabeira). 1997. 76f. Dissertação (Mestrado em Biologia Vegetal) - Instituto de Ciências Biológicas da Universidade Estadual de Brasília.

HARTMANN, H.T. et al. Plant propagation: principles and practices. 7.ed. New Jersey: Prentice-Hall, 2002. 896p.

HOFFMANN, A. et al. Fruticultura comercial: propagação de plantas frutíferas. Lavras: UFLA/FAEPE, 1996. 319p.

HU, C.Y.; WANG, P.J. Meristem, shoot tip, and cultures. In: EVANS, D.A. et al. (Ed). Handbook of plant cell culture. New York: MacMillan, 1983. V.1, p.177-227.

KIELSE, P.V.N. et al. Desinfestação e germinação in vitro de sementes de Parapiptadenia rigida (Bentham) Brenam. Revista Brasileira de Biociências, Porto Alegre, v.5, supl.2, p.141-
143, 2007. Disponível em: <http://www6.ufrgs.br/seerbio/ojs/ index.php/rbb/article/viewArticle/161>.

LEONEL, S. et al. Enraizamento de estacas de Lichia (Litchi chinensis Sonn). Scientia Agrícola, Piracicaba, v.52, n.2, p.335-338, 1995. Disponível em: <http://www.scielo.br/scielo.php?pid=S010390161995000200022\&script=sci_arttext\&tlng=pt>. Doi:10.1590/ S0103-90161995000200022.

LLOYD, G.; McCOWN, B.H. Commercially-feasible micropropagation of mountain laurel, Kalmia latifolia, by use of shoot-tip culture. International Plant Propagators Society Combined Proceedings of Annual, Washington, v.30. p.421-427, 1980.

LORENZI, H. Árvores brasileiras: manual de identificação e cultivo de plantas arbóreas do Brasil. Nova Odessa: Instituto Plantarum de Estudos da Flora, 2000. V.1.

MANTOVANI, N.C. et al. Micropropagação da caixeta (Didymopanax morototoni (Aubl) Dene. Et Planch). Ciência Florestal, Santa Maria, v.9, n.1, p.47-61, 1999. Disponível em: <http://www.ufsm.br/cienciaflorestal/sumarios/V9N1P.html $>$.

NOBRE, J.;ROMANO, A.. In vitro cloning of Ficus carica L. adult trees. Acta Horticulturae, Amsterdam, n.480, p.161164, 1998. Disponível em: <http://www.actahort.org/books/ 480/480_27.htm>.

SKOOG, F.; MILLER, C.O. Chemical regulation of growth and organ formation in plant tissues cultured in vitro. Symp Soc Exp Biol., Cambridge, n.11, p.118-131, 1975.

SOBRAL, M. et al. Flora arbórea e arborescente do Rio Grande do Sul. Porto Alegre: Rima-NovoAmbiente. 2006. 350p.

SOUZA, A.V. et al. Germinação de embriões e multiplicação in vitro de Lychnophora pinaster Mart. Ciência e Agrotecnologia, Lavras, p.1532-1538, 2003. (Edição especial). Disponível em: <http://www.editora.ufla.br/revista/ suple_2003/Vol27_Esp.htm $>$.

TAIZ, L.; ZEIGER, E. Fisiologia vegetal. 3.ed. Porto Alegre:Artmed, 2004. 719p. 